\title{
CORRIGENDUM
}

\section{Bioimpedance spectroscopy in the infant: effect of milk intake and extracellular fluid reservoirs on resistance measurements in term breastfed infants}

Z Gridneva, AR Hepworth, LC Ward, CT Lai, PE Hartmann and DT Geddes

European Journal of Clinical Nutrition (2016) 70, 865; doi:10.1038/ejcn.2016.68

Correction to: European Journal of Clinical Nutrition (2016) 70, 843-851; doi:10.1038/ejcn.2016.26; published online 30 March 2016

Since the publication of this article, the authors have noticed that several ranges in Table 1 were incorrectly presented or converted and the following corrections are required:

Feed duration range at 5 months reads Dec-46, should be 12-46.

Feed duration total range reads Dec-85, should be 12-85.

Bladder volume range at 12 months for pre-feed reads Jun-50, should be $6-50$.
Bladder volume range at 12 months for post-feed reads Aug-51, should be $8-51$.

Free-water change range at 12 months reads -138 , should be -29-109.

Free-water change range for Total reads -366 , should be -29-337.

The PDF and online versions have also been amended. The authors apologise for any inconvenience caused. 